DOI: 10.12731/2070-7568-2017-2-80-87

УДК 327

\title{
ПОИСК МЕТОДОВ РЕШЕНИЯ \\ ПОЛИТИЧЕСКИХ ВОПРОСОВ НА ЮЖНОМ КАВКАЗЕ
}

Карадемир Г.С.

В данной статье освещены наиболее узловые противоречия, имеющие место быть на современном витке истории между политическими элитами Баку, Анкарой и Еревана. Минуя длительную историю дипломатических связей между Азербайджаном и Туричей, автор статьи сосредоточил основное внимание на ключевых вопросах военных доктрин и политике невмешательства в дела других государств. Выяснено, что Азербайджан и Туриию объединяют языковые, этнографические и географические факторы. В свою очередь эти страны ищут мира с Арменией, чтобы с большим успехом реализовывать собственную политическую линию.

Цель статьи: Показать некоторые пути и методы конструктивной стратегии мира, взаимопонимания и сотрудничества между Туриией, Азербайджаном и Арменией.

Метод или методология проведения работы. В основу работы положен метод сравнительно-исторического анализа.

Результаты: Идеологические расхождения в политических интересах и приоритетах Туриии, Азербайджана и Армении, ряд трудностей, возникающих на извилистом пути во взаимоотношениях руководителей закавказских республик, не должны поколебать стратегическое партнёрство этих стран. Альтернативь миру и взаимовыгодному сотрудничеству нет.

Область применения результатов. Результаты исследования могут быть использованы в учебном прочессе при подготовке к лекциям и семинарам по курсу международных отномений.

Ключевые слова: армяно-туреицие отночения; азербайджанотуреикие связи; политическая стратегия; внешнеполитические ориентиры; Нагорно-Карабахский конфликт. 


\section{SEARCH FOR METHODS FOR SOLVING POLITICAL ISSUES IN THE SOUTH CAUCASUS}

Karademir H.S.

This article highlights the most nodal contradictions taking place on the modern historical format between the political elites of Baku, Ankara and Yerevan. Passing the long history of diplomatic relations between Azerbaijan and Turkey, the author focused on the key issues of military doctrines and the policy of non-interference in the affairs of other states. It was found out that Azerbaijan and Turkey are united by linguistic, ethnographic and geographical factors. In turn, these countries are looking for peace with Armenia, so as to successfully implement their own political line.

Purpose - to show some ways and methods of a constructive peace strategy, mutual understanding and cooperation between Turkey, Azerbaijan and Armenia.

Methodology. The research is based on the method of comparative-historical analysis with elements of the author's comment is laid.

Results. Ideological differences in the political interests and priorities of Turkey, Azerbaijan and Armenia, a number of difficulties arising on the winding path in the relations of the leaders of the Transcaucasian republics, should not shake the strategic partnership of these countries. There is no alternative to peace and mutually beneficial cooperation

Practical implications. The results of the study can be used in the educational process to prepare for lectures and seminars on international relations.

Keywords: Armenian-Turkish relations; Azerbaijani-Turkish relations; Political strategy; Foreign policy guidelines; The Nagorno-Karabakh conflict.

В последние годы Азербайджан активно развивает и укрепляет связи с рядом исламских стран. Прежде всего это относится к Турции, которая является его давним стратегическим партнёром. Азер- 
байджан и Турция в 2010-2016 годах, хотя и с переменным успехом, но всё же развивали стабильные политические отношения, позиции двух стран по международным вопросам также совпадали. Автор данной статьи считает, что новый виток сотрудничества будет содействовать их сближению по ряду вопросов, симптоматично усилит инвестиционную деятельность.

Кавказское направление в решении некоторых задач возникло в Турции не сразу. Правительство Турции настойчиво ищет пути и методы сближения с Россией и закавказскими республиками. Надо честно признать, что с Баку выискивать такие причины не было необходимости. Во-первых, в отличие от администрации Аяза Муталибова и главы правительства Народного Фронта Абульфаза Эльчибея, между Гейдаром Алиевым и его турецким коллегой Сулейманом Демирелем установились весьма доверительные отношения. Во-вторых, положительно сказывается ряд факторов этно-политической зависимости и географической близости. А именно: единая языковая группа, приближённость границ. В-третьих, турецкие политологи, политики и экономисты с каждым годом всё настойчивее говорят о «глубоких историко-культурных корнях страны на Ближнем Востоке, Балканах, в Центральной Азии, на обширной территории Большого Кавказа» [7]. Суммируя указанное, можно утверждать, что с начала 1990-х годов тесные политические контакты между Баку и Анкарой всё более крепли, сохраняя в ЮжноКавказском регионе явно приоритетный характер.

С конца 1990-х годов отмечено заметное потепление отношений Баку и Анкары также с Москвой. В наши дни пала стена недоверия, которая, увы, была скоропалительно воздвигнута Б.Н. Ельциным; далее, контакты глав правительства Азербайджана с Президентом РФ В.В. Путиным, бесспорно, стали гораздо более активными. Взаимовыгодными она оказались и для Турции.

Как подчёркивает Р. Мусабеков, «фактор личностных взаимоотношений Баку, Анкары и Москвы с началом нового тысячелетия стал играть важную роль. Она усиливается в связи с тем обстоятельством, что Азербайджан с 2000-х годов начал получать 
большие нефтяные доходы, что позволяло достигать в буквальном смысле фантастических темпов роста экономики, а также резкого повышения жизненного уровня местного населения. Азербайджан, ранее остро нуждавшийся в технической и финансовой помощи извне, дипломатической и политической поддержке, постепенно превращается в уверенное в себе и стабильное государство» [5, с. 42-43]. Повышение геополитического веса отразилось на взаимоотношениях со всеми ведущими политическими партнёрами, в первую очередь включая Россию и Турцию.

Турция и Азербайджан на современном этапе являют собой показательный пример взаимовыгодного стратегического партнёрства в военно-политической сфере. Анкара открыто и безапелляционно выступает на стороне Азербайджана в Нагорно-Карабахском конфликте. В свою очередь пути урегулирования отношений с Арменией продиктованы стратегией, цель которой вовлечь Ереван в выгодные международные политико-экономические проекты, что потенциально скоординирует для Турции определённый объём энергетических и транспортных коммуникаций. Непоследовательная политика подвигла Турцию к достаточно неоднозначным решениям. Однако с течением времени даже самые малые осколки нынешней реальности, которые были раздроблены противоречиями, укладываются в строгий политический курс.

С сентября 2008 года между Турцией и Арменией наступает период «политической оттепели». В результате - частичное восстановление дипломатических отношений между Турцией и Арменией. Осенью 2009 года в Цюрихе был подписан и ратифицирован «Протокол о развитии двусторонних отношений». Согласно нему, Анкара и Ереван взяли на себя ответственность за уважение принципов суверенитета, равенства и сохранения территориальной целостности. Речь шла прежде всего о нерушимости границ и невмешательстве во внутренние дела иных стран-государств.

Одновременно с тем Цюрихский протокол стал подлинным испытанием на прочность позиции официального Баку, который пытался опротестовать некоторые его положения в связи с нормализацией ар- 
мяно-турецких отношений и одновременным замалчиваем Карабахской проблемы. Турция вновь оказалась в противоречивой ситуации. На этот раз на место бывшей сильной движущей силы пришла неопределённость. Политическая баланс сил и интересов нарушился. Баку настаивал на том, чтобы Анкара решала две эти проблемы параллельно. Это вполне естественно выстроенная генеральная линия для политики Азербайджана. Официальный Баку не столь серьёзно волновала проблема разрешения армяно-турецких отношений, сколько оккупация почти 20\% исконно местных земель Арменией. Анкара, в свою очередь, более всего была обеспокоена отсутствием нормализации собственных выгодных связей с Арменией. Однако Баку твёрдо стоял на своих изначальных позициях, и в конечном итоге Анкара вынуждена была заявить о том, что границы с Арменией откроются лишь после того, как армянские военизированные формирования приступят к реальному (а не на бумагах) освобождению оккупированных территорий Азербайджана. Строго говоря, это напоминало ультиматум. Министр обороны Азербайджана С. Абиев утвердительно заявил: «Если Армения не освободит азербайджанские земли, начало большой войны на Южном Кавказе неизбежно» [1].

Как поясняет А.В. Глазова, «Анкара согласилась с заявлением Баку о том, что Цюрихский протокол в вышеуказанной части противоречит национальным интересам Азербайджана» [3, с. 77]. Итак, получалось, что этнической и языковой близости недостаточно для объединения тюрок в единый и прочный союз под флагманом Турции. Хотя напряжённость годами всё же не снималась, общественное мнение Турции заняло азербайджанскую сторону.

В связи с заявленной в статье темой, необходимо детально изучить официальную позицию руководства Армении. Если альтернативы миру не будет, то не попадёт ли Армения в своеобразный «геополитический тупик»? Попытаемся высказать независимую точку зрения. Что теряет Ереван, рассорившись со своими кавказскими соседями? В августе 2016 года бывший мэр Еревана и член партии «Армянский национальный конгресс» Ваагн Хачатрян заявил: «Многим бы хотелось иметь соседа с такой развитой экономикой, 
как у Турции, а мы этим не пользуемся» [2]. Эти слова согласуются с реальными обстоятельствами. «Турция - это важный политический и экономический партнёр для Азербайджана, и этого нельзя Армении сбрасывать со счетов» [4, с. 6]. В свою очередь Председатель парламентского комитета по международным отношениям С. Сеидов на официальном уровне примирительно заявил: «Если руководство Еревана пожелает, то Армения может стать неотъемлемой и составной частью Азербайджана» [6, с. 2].

Таким образом, приходим к выводу, что между Баку, Анкарой и Ереваном - клубок тесно переплетённых проблем. Далеко не всегда в истории Турции и закавказских республик они были разрешены на взаимовыгодном и взаимоприемлемом уровне. Многие проблемы долгие годы оставались (к сожалению, отчасти остаются и в наши дни) нерешёнными.

Самый болезненный вопрос для сопредельных государств на территории Южного Кавказа - это Нагорно-Карабахский конфликт. Он разгорелся ещё в далёком 1988 году и продолжается до настоящих дней. Полагаем, что наиболее конструктивными путями в деле его урегулирования могут явиться мирные диалоги между Азербайджаном и Арменией на Саммитах и Конференциях. Причём, острая и застарелая проблема должна решаться не кулуарно, а при активном участии стран-сопредседателей Минской группы ОБСЕ, глав-делегаций МИДа двух государств и, желательно, высшего руководящего состава ОИС. Необходимо понимать, что военное вмешательство - это гибельный путь, а альтернативы добрососедским переговорам нет. И, конечно, необходим постепенный вывод армянских войск с территории оккупированных земель. В таком случае появятся веские основания полагать, что конфликт будет успешно решён в позитивном аспекте.

\section{Список литературы}

1. Абиев С. Начало большой войны на Южном Кавказе неизбежно // Центральная Азия, 2010, 26 февраля. URL: http://www.centrasia.ru/ newsA.php?st=1267157940. 
2. В изоляции Армении виноват Саргсян - Армянские политики признаются. 2017, 23 февраля. URL: http://news.day.az/politics/872046.html

3. Глазова А.В. Внешнеполитические инициативы Турции на Южном Кавказе: успех или неудача? // Проблемы национальной стратегии, № 1, 2001. С. 66-81.

4. Нуриева Т. Альтернативы миру нет // Каспий, 28 февраля, 2017.

5. Мусабеков Р. Азербайджан между Турцией и Россией // Россия и мусульманский мир, 2012, № 1. С. 40-51.

6. Сеидов С. Армения может стать губернией Азербайджана // Бакинский рабочий, 16 февраля, 2017.

7. Principles of Turkish Foreign Policy and Regional Political Structuring by Ahmet Davutoglu. 2012, Third edition. http://ankara.embassy.si/fileadmin/user_upload/dkp_16_van/docs/Principles_of_Turkish_Foreign Policy_and_Regional_Political_Structuring_by_Ahmet_Davutoglu.pdf

\section{References}

1. Abiyev S. Nachalo bolshoy voyny na Yuzhnom Kavkaze neizbezhno [The beginning of a big war in the South Caucasus is inevitable]. Tsentralnaya Aziya. February 26, 2010.

2. Vizolyatsii Armenii vinovat Sargsyan-Armyanskiye politiki priznayutsya [Sargsyan is to blame for Armenia's isolation - Armenian politicians admit]. February 23, 2017.

3. Glazova A.V. Vneshnepoliticheskiye initsiativy Turtsii na Yuzhnom Kavkaze: uspekh ili neudacha? [Turkey's foreign policy initiatives in the South Caucasus: success or failure?]. Problemy natsionalnoy strategii. № 1. 2001, pp. 66-81.

4. Nuriyeva T. Alternativy miru net [There is no alternative to the world]. Kaspiy. February 28, 2017.

5. Musabekov R. Azerbaydzhan mezhdu Turtsiyey i Rossiyey [Azerbaijan between Turkey and Russia]. Rossiya i musulmanskiy mir. 2012. № 1, pp. $40-51$.

6. Seidov S. Armeniya mozhet stat guberniyey Azerbaydzhana [Armenia can become the province of Azerbaijan]. Bakinskiy rabochiy. February 16, 2017. 
7. Principles of Turkish Foreign Policy and Regional Political Structuring by Ahmet Davutoglu. 2012, Third edition. http://ankara.embassy.si/ fileadmin/user_upload/dkp_16_van/docs/Principles_of_Turkish_ Foreign_Policy_and_Regional_Political_Structuring_by_Ahmet_ Davutoglu.pdf

\section{ДАННЫЕ ОБ АВТОРЕ}

Карадемир Гасан Сиддик оглу, докторант кафедры международных отношений

Бакинский славянский университет

ул. С. Рустама, 33, г. Баку, АZ 1014, Азербайджан

sevinc.n@mail.ru

\section{DATA ABOUT THE AUTHOR}

Karademir Hasan Siddik, postgraduate student of the Department of International relation Baku Slavic University 33, Suleyman Rustam Str., Baku, AZ 1014, Republic of Azerbaijan sevinc.n@mail.ru 